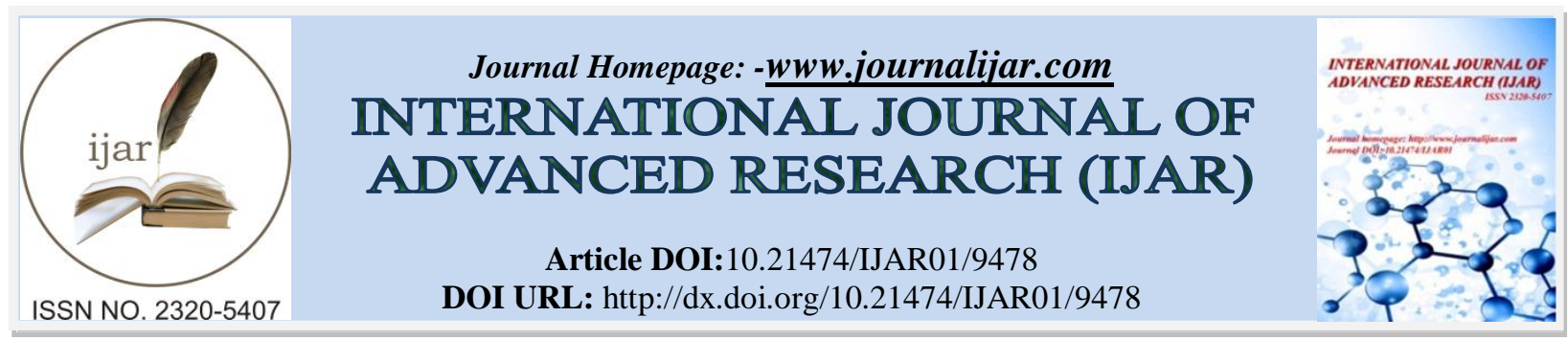

RESEARCH ARTICLE

\title{
A STUDY ON KNOWLEDGE ABOUT HEALTH AND NUTRITION OF THE HILL KORWAS OF SURGUJA DISTRICT, CHHATTISGARH: AN ANALYTICAL ASSESSMENT
}

Irshad Khan ${ }^{1}$, Nagma Parvin ${ }^{2}$ and Somen Kumar Pradhan ${ }^{3}$.

1. Project Technical Officer, ICMR-NIRT, Chennai, STDC, Raipur, Chhattisgarh, India.

2. Junior Research Fellow, Department of Anthropology, West Bengal State University, West Bengal, India.

3. Scientist-C (Medical), ICMR-NIRT, Chennai, STDC, Raipur, Chhattisgarh, India.

\section{Manuscript Info}

Manuscript History

Received: 03 June 2019

Final Accepted: 05 July 2019

Published: August 2019

Key words:-

Hill Korwa Tribe, Knowledge, Health,

Nutrition.

\begin{abstract}
The present study was undertaken to assess the knowledge about health and nutrition of the Hill Korwa Tribe of Surguja district, Chhattisgarh. Hill Korwa is one of the PVTGs of Chhattisgarh. A total of 307 households (142 males and 165 females) of Surguja district were selected purposively and interviewed through the help of a pre-tested structured scheduled for the collection of data on health and nutrition education. The results shows that nutritional knowledge of the Hill Korwas was unsatisfactory and they need in-depth education on nutrition and intervention programmes for holistic development of tribal people of Chhattisgarh. The present study was states that nearly $1 \%$ of them have very good knowledge about basic ideas on health and nutrition and also highlights the knowledge about conservation of nutrients. Out of the results it was states that both males and females have good idea about it, but the knowledge about nutrition for vulnerable groups is poor among most of the males and females of Hill Korwas. One of the important issues is that good knowledge about health and hygiene is present only $8 \%$ among males and only $10.3 \%$ among females. However, it may be inferred after assessing overall scores that in all cases score of knowledge about the health and nutrition among the females is quite better than males of Hill Korwa tribes.
\end{abstract}

Copy Right, IJAR, 2019,. All rights reserved.

\section{Introduction}

We know in basically that tribal people are the most conservative, orthodox and superstitious, which impede their growth and development in all walks of life. Most of tribes are poor, backward and generally lead a hard and miserable life. Tribes are forced to rehabilitate due to the part of development efforts, in a totally new settlement. ${ }^{[1]}$

According to 2011 census, in India 8.6 percent are tribal population out of the total population. Daily diets of the tribal's are different from the entire population as they include certain uncommon foods different from the cooking manner. ${ }^{[2]}$ Their lifestyles and food habits are different from that of their rural or tribal neighbours. Most of them mainly depend on minor forest produce and manual labour for livelihood and not having adequate income. Their

Corresponding Author:- Dr. Irshad Khan

Address:- State TB Training and Demonnstaration Center, District Hospital Campues, Raipur, Chhattisgarh. India. 
food consumption pattern is dependent on the vagaries of nature and varies from extreme deprivation in the lean seasons and high intakes in the post-harvest period. ${ }^{[3]}$

The importance of proper nutrition as one of the enhancing the nutrition attitudes, aspects of lifestyle were emphasized in the recent years and the trend toward healthier diets has increased ${ }^{[4,5]}$ Evidences of Epidemiology indicate that in recent years changes in lifestyle increased the incidence of major diseases (such as: cardiovascular disease, cancer, osteoporosis, high blood pressure and obesity), change in nutrition habits can be noted as an important change. Nutrition education as one of the important practical aspects of nutrition knowledge, play an important role in raising public awareness and ultimately health of society. ${ }^{[6]}$

The education about nutrition as means of translating nutritional requirement in to food, and adjusting the food choices to satisfy nutritional, cultural, psychological and economic needs ${ }^{[7]}$ Education on nutritional knowledge is the process by which beliefs; attitudes, environmental influences and understanding about food are converted into practices, which are nutritionally sound and consistent with individual needs, purchasing power, available food sources, and socio-cultural background. Effective nutritional education results not only in the acquisition of knowledge and skill, but also desirable changes in the eating habits of learners. ${ }^{[8]}$

To the best of our knowledge at anthropological point of view, especially in India the researches about tribal nutrition and sufficient information are not available. So, the purpose of this study was to evaluate the nutrition knowledge, attitude and food habits of Hill Korwas and provide solutions that enhances and improves awareness and knowledge of these poor and needy people to choose healthy and appropriate foods in order to maintain their health.

\section{Materials and Methods:-}

Hill Korwa, a sub group of Korwa tribe was identified as a Particular Vulnerable Tribal Group (PVTGs) during the fifth five year plan ${ }^{[9]}$ They are distributed in the Surguja, Jashpur, Balraampur, Shankargarh and Korba district and their total population is $34,122 .{ }^{[10]}$ According to anthropological description of family, they belong to Austro-Asiatic family. ${ }^{[11]}$ The present study was conducted among the purposive randomly selected Hill Korwa tribe of Surguja district of Chhattisgarh. The present study was carried out mainly in three blocks namely Lundra, Batauli and Sitapur of Surguja district of Chhattisgarh. In this study, 16 gram panchayat comprising 26 villages were covered where Hill Korwas are predominately residing.

A cross sectional survey was conducted in 2015- 2016 on Hill Korwa male and female, aged between 15 to 45 years. A total of 307 households (142 males and 165 females) of Surguja district were selected purposively and interviewed through the help of a pre-tested structured scheduled for the collection of data.

During the time of collecting the information, basic general discussions with the locals were also been considered for collecting the general information of the people and area. Generally nutrition education was carried out using pretested schedule. ${ }^{[12]}$ So pretested schedules were prepared for collecting the data from the research participants, which contains basic information like age, sex and general information for qualitative data in-depth interviews and observation were carried out in the field. A questionnaire was made to assess the nutrition and health concept of the individual.

Questions on nutritional knowledge were composed of eight items including the functions of basic of health and nutrition (7 items), nutrition for vulnerable section (12 items), Conservation of nutrients (5 items), Food and cooking Practices (7 items), Immunization (5 items), Health and Hygiene (10 items), Environmental Sanitation (5 items), Social participant (6 items). The questions included in the schedule were of 'Yes/No/Don't know' type. For each correct answer, one mark was allotted and for wrong answer, zero mark was given. On the basis of wide variations in the scores obtained by the subject, nutritional knowledge was divided into four categories viz. Very good (80\% and above), good (60-79\%), average (40-59\%), poor (30-39\%), very poor $(<30 \%)$.

All the data were analyzed by Microsoft office excel and by the use of SPSS (version 22.0) statistical software package. 


\section{Ethical Considerations}

The study was approved by the institutional ethics committee of Central University of Orissa, Koraput (Odisha). The participants were briefed about the purpose and nature of the study, all the data was collected after verbal consent of the studied participants.

\section{Results and Discussion:-}

In table 1 the knowledge about basics of health and nutrition scores of the Hill Korwas is reflected. Majority of both male and female of Hill Korwas have average knowledge about the basics of health and nutrition (males 64.1\%, females $59.4 \%$ ) followed by very poor (males $22.5 \%$, females $25.5 \%$ ), and good (12\% males, $14 \%$ females) knowledge. Only $1 \%$ of them have very good knowledge about it. Knowledge about conservation of nutrients is good among majority of males (41\%) females (49\%) followed by average (males $29 \%$, females $30 \%$ ) and very good (males 25\%, females 19\%) knowledge. Very poor knowledge about it is observed only among 5\% males and $2 \%$ females. Beliefs and knowledge of Hill Korwas on food and cooking practices scores are depicted in table 1. More than $60 \%$ of both males and females have average knowledge on it followed by good (27.0\%) and very good (4.9\%), very poor $(5.5 \%)$ knowledge [Table 1$]$.

Table 1:-Knowledge about Basics of health and nutrition, Conservation of Nutrients, Food and cooking Practices and Nutrition for Vulnerable Scores of the Hill Korwas

\begin{tabular}{|c|c|c|c|c|c|c|c|c|c|c|c|}
\hline \multirow[t]{2}{*}{ Gender } & \multicolumn{11}{|c|}{$\begin{array}{l}\text { Knowledge about health and nutrition grades } \\
(\mathrm{n}=\text { male-142, Female-165) }\end{array}$} \\
\hline & \multicolumn{2}{|c|}{$\begin{array}{c}\text { Very Good } \\
\text { (80\% and } \\
\text { above }) \\
\end{array}$} & \multicolumn{2}{|c|}{$\begin{array}{l}\text { Good }(60- \\
70 \%)\end{array}$} & \multicolumn{2}{|c|}{$\begin{array}{c}\text { Average } \\
(40-59 \%)\end{array}$} & \multicolumn{2}{|c|}{$\begin{array}{l}\text { Poor (30- } \\
\text { 39\%) }\end{array}$} & \multicolumn{2}{|c|}{$\begin{array}{l}\text { Very Poor } \\
(<30 \%)\end{array}$} & $\begin{array}{l}\text { Mean Percentage } \\
\text { Score }\end{array}$ \\
\hline \multicolumn{12}{|c|}{ Basics of Health and Nutrition Score } \\
\hline & No. & $\%$ & No. & $\%$ & No. & $\%$ & No. & $\%$ & No. & $\%$ & Average score $\%$ \\
\hline Male & 2 & 1.4 & 17 & 12.0 & 91 & 64.1 & 0 & 0.0 & 32 & 22.5 & $47 \%$ (Average) \\
\hline Female & 2 & 1.2 & 23 & 13.9 & 98 & 59.4 & 0 & 0.0 & 42 & 22.5 & $47 \%$ (Average) \\
\hline Total & 4 & 1.3 & 40 & 13.0 & 189 & 61.6 & 0 & 0.0 & 74 & 24.1 & $47 \%$ (Average) \\
\hline \multicolumn{12}{|c|}{ Conservation of Nutrients Score } \\
\hline Male & 36 & 25.0 & 58 & 41.0 & 41 & 29.0 & 0 & 0.0 & 7 & 5.0 & $56 \%$ (Average) \\
\hline Female & 31 & 19.0 & 81 & 49.0 & 49 & 30.0 & 0 & 0.0 & 4 & 2.0 & $56 \%$ (Average) \\
\hline Total & 67 & 22.0 & 139 & 45.0 & 90 & 29.0 & 0 & 0.0 & 11 & 4.0 & $58 \%$ (Average) \\
\hline \multicolumn{12}{|c|}{ Food and cooking Practices Score } \\
\hline Male & 6 & 4.2 & 38 & 26.8 & 88 & 62.0 & 0 & 0.0 & 10 & 7.0 & $56 \%$ (Average) \\
\hline Female & 9 & 5.5 & 45 & 27.3 & 104 & 63.0 & 0 & 0.0 & 7 & 4.2 & $58 \%$ (Average) \\
\hline Total & 15 & 4.9 & 83 & 27.0 & 192 & 62.5 & 0 & 0.0 & 17 & 5.5 & $57 \%$ (Average) \\
\hline \multicolumn{12}{|c|}{ Nutrition for Vulnerable Score } \\
\hline Male & 0 & 0.0 & 0 & 0.0 & 46 & 32.0 & 38 & 27.0 & 58 & 41.0 & $33 \%$ (Poor) \\
\hline Female & 0 & 0.0 & 2 & 1.0 & 52 & 32.0 & 51 & 31.0 & 60 & 36.0 & $34 \%$ (Poor) \\
\hline Total & 0 & 0.0 & 2 & 1.0 & 98 & 31.9 & 89 & 29.0 & 118 & 38.0 & $33 \%$ (Poor) \\
\hline
\end{tabular}

Table 2 defines the majority of males and females have very poor knowledge about nutrition for vulnerable groups. $32 \%$ of both sex have average knowledge followed by poor (male $27 \%$, female $31 \%$ ). Not a single male scored good or very good category but only two (1\%) females scored in good category. Maximum of males (76.1\%) and females $(65.5 \%)$ have very poor knowledge about immunization followed by average (male $18.3 \%$, females $25.5 \%$ ) and good knowledge. Merely $0.7 \%$ males and $0.6 \%$ females have very good knowledge about immunization. Maximum $(44 \%)$ Hill Korwas have average knowledge about health and hygiene followed by poor $(23.8 \%)$, very poor $(22.5 \%)$ and good knowledge about it. No male but only one $(0.3 \%)$ female have very good knowledge about it. Therefore females of Hill Korwa have quite better knowledge than their male counterparts on health and hygiene. Maximum males $(60.6 \%)$ and females $(50.9 \%)$ have very poor knowledge about environmental sanitation. Therefore it is clear that the knowledge among females is little bit advance than males Hill Korwa on environmental sanitation. Most of the Hill Korwas (Males-47.2\%, females-40 \%) have good knowledge about social participation followed by average (Males-30.3\%, females-38.2\%), very good (Males-17.6\%, females-15.2\%), and very poor (Males-4.9\%, females$6.7 \%)$ knowledge. Therefore it is concluded that with regards to social participation, the knowledge of female is better than male Hill Korwas [Table 2]. 
Table 2:-Knowledge about Immunization, Health and Hygiene, Environmental Sanitation, Social participation score among the Hill Korwas

\begin{tabular}{|c|c|c|c|c|c|c|c|c|c|c|c|}
\hline \multirow[t]{2}{*}{ Gender } & \multicolumn{11}{|c|}{$\begin{array}{l}\text { Knowledge about health and nutrition grades } \\
(\mathrm{n}=\text { male-142, Female-165) }\end{array}$} \\
\hline & \multicolumn{2}{|c|}{$\begin{array}{l}\text { Very Good }(80 \% \\
\text { and above) }\end{array}$} & \multicolumn{2}{|c|}{$\begin{array}{l}\text { Good (60- } \\
\text { 70\%) }\end{array}$} & \multicolumn{2}{|c|}{$\begin{array}{l}\text { Average } \\
(40-59 \%)\end{array}$} & \multicolumn{2}{|c|}{$\begin{array}{l}\text { Poor (30- } \\
\text { 39\%) }\end{array}$} & \multicolumn{2}{|c|}{$\begin{array}{c}\text { Very Poor } \\
(<30 \%)\end{array}$} & $\begin{array}{c}\text { Mean Percentage } \\
\text { Score }\end{array}$ \\
\hline \multicolumn{12}{|c|}{ Immunization Score } \\
\hline & No. & $\%$ & No. & $\%$ & No. & $\%$ & No. & $\%$ & No. & $\%$ & Average score $\%$ \\
\hline Male & 1 & 0.7 & 7 & 4.9 & 26 & 18.3 & 0 & 0.0 & 108 & 76.1 & $21 \%$ (Very Poor) \\
\hline Female & 1 & 0.6 & 14 & 8.5 & 42 & 25.5 & 0 & 0.0 & 108 & 65.5 & $25 \%$ (Very Poor) \\
\hline Total & 2 & 0.7 & 21 & 6.8 & 68 & 22.1 & 0 & 0.0 & 216 & 70.4 & $23 \%$ (Very Poor) \\
\hline \multicolumn{12}{|c|}{ Health and Hygiene score } \\
\hline Male & 0 & 0.0 & 12 & 8.0 & 66 & 46.0 & 34 & 24.0 & 30 & 21.0 & $37 \%$ (Poor) \\
\hline Female & 1 & 0.6 & 17 & 10.3 & 69 & 41.8 & 39 & 23.6 & 39 & 23.6 & $36 \%$ (Poor) \\
\hline Total & 1 & 0.3 & 29 & 9.4 & 135 & 44.0 & 73 & 23.8 & 69 & 22.5 & $37 \%$ (Poor) \\
\hline \multicolumn{12}{|c|}{ Environmental Sanitation score } \\
\hline Male & 1 & 0.7 & 11 & 7.7 & 44 & 31.0 & 0 & 0.0 & 86 & 60.6 & $26 \%$ (Very Poor) \\
\hline Female & 4 & 2.4 & 19 & 11.5 & 58 & 35.2 & 0 & 0.0 & 0 & 0.0 & $29 \%$ (Very Poor) \\
\hline Total & 5 & 1.6 & 30 & 9.8 & 102 & 33.2 & 0 & 0.0 & 170 & 55.4 & $28 \%$ (Very Poor) \\
\hline \multicolumn{12}{|c|}{ Social participation } \\
\hline Male & 25 & 17.6 & 67 & 47.2 & 43 & 30.3 & 0 & 0.0 & 7 & 4.9 & $55 \%$ (Average) \\
\hline Female & 25 & 15.2 & 66 & 40.0 & 63 & 38.2 & 0 & 0.0 & 11 & 6.7 & $53 \%$ (Average) \\
\hline Total & 50 & 16.3 & 133 & 43.3 & 106 & 34.5 & 0 & 0.0 & 18 & 5.9 & $54 \%$ (Average) \\
\hline
\end{tabular}

Table 3:-Total Score of Knowledge about Health and Nutrition among the Hill Korwas

\begin{tabular}{|c|c|c|c|}
\hline Knowledge about Health and Nutrition & Males \% & Females \% & Total \% \\
\hline Basics of Health and Nutrition Score & 47 & 47 & 47 \\
\hline Conservation of Nutrients Score & 56 & 56 & 58 \\
\hline Food and cooking Practices Score & 56 & 58 & 57 \\
\hline Nutrition for Vulnerable group Score & 33 & 34 & 33 \\
\hline Immunization Score & 21 & 25 & 23 \\
\hline Health and Hygiene Score & 37 & 36 & 37 \\
\hline Environmental Sanitation Score & 26 & 29 & 28 \\
\hline Social participant Score & 55 & 53 & 54 \\
\hline Mean Percentage Score & $43 \%$ (Average) & $44 \%$ (Average) & $43 \%$ (Average) \\
\hline
\end{tabular}

Table 3 exhibits the total score of knowledge about the health and nutrition among the Hill Korwas. Males and females have equal scores about knowledge on basics of health and nutrition $(47 \%)$ and conservation of nutrients (56\%). Females scored higher than males in knowledge about food and cooking practices (Males-56\%, females$58 \%$ ), nutrition for vulnerable group (Males-21\%, females-25\%), and environmental sanitation (Males-26\%, females-29\%). In rest two viz. health and hygiene (Males-37\%, females-36\%) and social participation (Males-55\%, females-53\%) females scored less than the male Hill Korwas. Overall, it can be inferred that females scored more than males on health and nutrition [Table 3].

\section{Conclusion:-}

With regard to the fact that high nutrition knowledge and attitude of physical education students are relate to their nutrition courses, according to poll results from the subjects in this research, $62.7 \%$ of subjects have been reported; lack of adequate information as one of the main factors in low nutrition knowledge and only $2 \%$ of subjects have nutrition license; therefore holding nutrition workshop and courses in university and even including nutrition and courses. In the curriculum can enhance their attitudes and nutrition behaviours and have a positive effect on them. In the present study it is well known fact that nutritional status is primarily linked with dietary habits as well as the ecology within which this population live in, so further research should be undertaken to investigate, in details on these factors. We know that each tribal population has its unique food habits.Also owing to limited nutrition studies in Hill Korwa of Surguja district and the important of promotion of nutrition knowledge and attitude for keeping the society healthy, further studies on this area seem necessary. 


\section{Financial Support and Sponsorship}

Nil

\section{Conflicts of Interest}

There are no confects of interest

\section{References:-}

1. Riji H. Nutritional status of Tribal and Non tribal preschool. Ind. J. Nutrition Dieted 2008; 45: 236.

2. Mittal P, Srivastava S. Diet, nutritional status and food related traditions of Oraon tribes of New Mal, West Bengal, India. Jan-Mar 2006; 6:385.

3. Kumar A. Health and Nutritional Status of Indian Women. New Delhi: Anmol publications Pvt. Ltd; 2006.

4. Margetts BM, Thempson RL, Speller V, Mcvey D. Factors which influence healthy eating pattern result from the 1993 health education authority health and life style survey in England. Public Health Nutrition 1998; 3: 193-98.

5. Stampfer M, Huf B, Mansen JE, Rimm EB. Primary Prevention of coronary heart disease in women through diet and life style. N Engel Journal of Medicine 2004; 6: 16-22.

6. Barzegari A. A study of Nutrition Knowledge, Attitudes and Food Habits of College Students, World Applied Sciences Journal 2011; 15: 1012-1017.

7. Albanese NG. A giant step in nutrition education school lunch. Journal Nutrition Education 1971; 1: 13-14.

8. Choi ES, Shin N, Jung E, Park H, Lee H, Song K. A study on nutrition knowledge and dietary behaviour of elementary school children in Seoul. Nutrition Research and Practice 2008; 2: 308-316.

9. Ota AB, Mohanty SC. Particularly Vulnerable Tribal Groups of Orissa: Anthropology of Health and Medicine. Odisha: SCSTRTI; 2005. p. 8-10.

10. Tribal Research Training Institute. Vikas Yojna. Raipur: Chhattisgarh Government; 2004.

11. Srivastava VK. The Pahari Korwas: Socio Economic condition and their Development. New Delhi: Sonali Publications; 2007.

12. Palta A. A Study on the Food Consumption Pattern and Nutrient Intake of the Oraons of Jashpur Nagar state. Bhopal: Bulletin Tribal Research Institute 1988;16: 1-2. 